\title{
Article
}

\section{I like who you like, but only if I like you: Female character affects mate-choice copying.}

\author{
Chu, Simon
}

Available at http://clok.uclan.ac.uk/4250/

Chu, Simon ORCID: 0000-0001-8921-4942 (2012) I like who you like, but only if I like you: Female character affects mate-choice copying. Personality and Individual Differences, 52 (6). pp. 691-695. ISSN 0191-8869

It is advisable to refer to the publisher's version if you intend to cite from the work. http://dx.doi.org/10.1016/j. paid.2011.12.029

For more information about UCLan's research in this area go to http://www.uclan.ac.uk/researchgroups/ and search for < name of research Group>.

For information about Research generally at UCLan please go to http://www.uclan.ac.uk/research/

All outputs in CLoK are protected by Intellectual Property Rights law, including Copyright law. Copyright, IPR and Moral Rights for the works on this site are retained by the individual authors and/or other copyright owners. Terms and conditions for use of this material are defined in the policies page.

\section{CLoK}

Central Lancashire online Knowledge www.clok.uclan.ac.uk

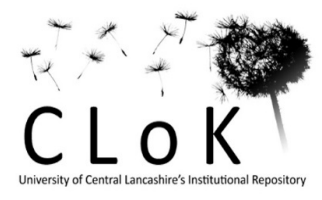


Chu, S. (2012). I like who you like, but only if I like you: Female character affects matechoice copying. Personality and Individual Differences, 52, 691-95.

doi:10.1016/j.paid.2011.12.029

I like who you like, but only if I like you: Female character affects mate-choice copying

Simon Chu

School of Psychology, University of Central Lancashire, Preston PR1 2HE

schu@uclan.ac.uk

\begin{abstract}
Mate-choice copying is shown when women imitate the mate-choice preferences of other women. We propose that the preferences of women with a pleasant character should be more influential than those of women with an unpleasant character and further suggest that this should apply only when the female demonstrates active interest in the male, rather than disinterest. Here, we presented women as having either a pleasant or unpleasant character and found that observing pleasant women looking at men increased women's preferences for those men, while observing unpleasant women looking at men had no effect on women's preferences. Furthermore, the effect of being looked at by a pleasant woman was heightened when she was smiling. This suggests that judgements of facial attractiveness can be socially influenced and that character affects the degree of influence.
\end{abstract}

Keywords: social influence; attractiveness; character; mate-choice

\title{
1. Introduction
}

When it comes to assessing the attractiveness of men, women can be influenced by other women relatively easily. For example, women rate men as being more desirable if the men are pictured with other women rather than pictured alone or with other men (Hill \& Buss, 2008) and men portrayed as married are rated as more physically attractive than men portrayed as being single (Eva \& Wood, 2006). Such effects show that women's assessment of men's desirability is influenced by their perceptions of other women's attitudes towards those same men. This has been broadly referred to as mate-choice copying to reflect the notion that this influence on women's preferences is based on imitating the preferences of other women (e.g. Graziano, Jensen-Campbell, Shebilske, \& Lundgren, 1993; Place, Todd, Penke, \& Asendorpf, 2010; Waynforth, 2007).

The main explanation for mate-choice copying effects is firmly rooted in the human evolutionary psychology approach to understanding human behaviour, and in particular, in Trivers' (1972) Parental Investment Theory. In this view, there is a substantial imbalance in 
the level of investment that each sex places in potential offspring such that the costs of reproduction, in terms of both time and energy, are greater for females than for males. Females should therefore be choosier than males in selecting potential partners and should place greater importance in a broader range of qualities such as social status, resourceholding potential and a willingness to invest in the female and the offspring (e.g. Furnham, 2009, although see Chu, Hardaker, \& Lycett, 2007). However, given that these aspects of an individual's worth as a partner are complex factors to assess, the value of an individual male as potential partner is often not easily discernible. Rather than engaging in a time-consuming (and perhaps resource-sapping) decision-making process with each potential candidate, females could circumvent the decision processes by imitating the decisions of other females who have already made these decisions (Pruett-Jones, 1992). Indeed, Hill and Buss (2008) describe a theoretical 'desirability assessment heuristic' that females may use which factors in the presence of other women when making judgements of the desirability of individual men. A further implication of this line of thinking however, is that women should differ in the degree of influence they have on other women's decisions about the desirability of men. Women who have more to offer in the mating market - that is, women with greater levels of youth, attractiveness and fecundity - should themselves be more demanding in the mating market than women with less to offer. Attractive women should be choosier than less attractive women. As such, the preferences of attractive women should carry more weight for other females than the preferences of less attractive women because attractive women can afford to be more selective in their partnership choices.

Only a few studies have specifically examined the degree to which a woman's attractiveness moderates her influence on other women's mate-choice preferences, but all have concluded that physically attractive women are more influential than less attractive women. For example, Waynforth (2007) asked women to rate the attractiveness of a set of male and female faces, and then later asked for a second rating of one of the male faces while it was depicted in a 'dating relationship' alongside one of the female faces. The attractiveness of the female partner was systematically varied and results showed that men paired with attractive female faces were later rated as being more attractive than they had been previously. In fact, men's initial attractiveness interacted with the attractiveness of the female partner; being paired with an attractive partner made little difference to attractive men but improved the ratings of unattractive men, while being paired with an unattractive partner reduced the ratings of attractive men but made little difference to unattractive men. Taken in concert with the small number of other investigations of this effect (e.g. Little, Burriss, Jones, DeBruine, \& Caldwell, 2008; Little, Caldwell, Jones, \& DeBruine, 2011; Yorzinski \& Platt, 2010), there is converging evidence that mate-choice copying, or mate quality bias (Vakirtzis \& Roberts, 2009), is moderated by the perceived physical attractiveness of the female being copied.

More broadly, it follows that women who are desirable should be more influential to other women's preferences than women who are less desirable. As one might expect, one factor that exerts a substantial influence on interpersonal desirability is character, and women who have positive character traits are perceived to be more desirable as both friends and romantic partners than women who have negative character traits (e.g. Lewandowski, Aron, \& Gee, 
2007; Paunonen, 2006). In fact, Lewandowski et al. (2007) showed that negative character traits actively reduced an individual's desirability in comparison to a control condition where no character information was provided. Therefore, given that character and desirability covary, is likely that character attractiveness may drive mate-choice copying effects in ways similar to physical attractiveness. Specifically, if desirable women are more influential to other women's preferences, and negative character reduces desirability, this implies that negative character should suppress mate-choice copying effects and it is this question that we examine.

According to Hill and Buss (2008), the presence of same-sex others has heuristic value in assessing the desirability of unknown opposite-sex targets, but such a heuristic operates in opposing ways for men and women; the presence of other men reduces a woman's desirability to men but the presence of other women enhances a man's desirability to women. Theoretically, other women enhance a man's desirability because he appears to be mated or at least desired by other women. However, such proposals do not differentiate between the presence of interested and disinterested females, a distinction which would be of enormous theoretical utility in an assessment of desirability. In an inventive naturalistic study using speed-dating interactions, Place et al. (2010) showed that women exhibited heightened interest in men who were seen to have a successful date with other women, but showed reduced interest in men they had seen with a disinterested date. Similarly, Jones, DeBruine, Little, Burriss and Feinberg (2007) found that seeing a smiling woman increased female participants' preferences for the face that she was smiling at, whereas seeing a woman with a neutral expression had the opposite effect. As such, the mere presence of a partner is not the only influence on perceptions of target desirability - these findings suggest that the degree of implied interest between a woman and a male target (even when this is rather coarsely manipulated) can exert powerful effects on the how the man is perceived.

Given that previous work suggests that men's attractiveness moderates the influence of female partners (Waynforth, 2007), we followed the procedure of Jones et al. (2007) who used a comparative measure of men's facial attractiveness that minimizes the influence of absolute attractiveness. In the pre-observation phase, women viewed pairs of male faces and rated which of the two faces they found to be more attractive. Then in the observation phase, they familiarized themselves with the faces of four women (who we refer to as models) who were characterized as having either a pleasant or unpleasant character, and then saw the same pairs of male faces with one of the models pictured in between them, facing one of the male faces (we refer to this male face as the target) with either a neutral expression or a smiling expression. Finally, in the post-observation phase, women again rated the pairs of male faces in the same way as before. We predicted that women's preferences would shift towards the target faces that were being observed by smiling models and, in particular, towards those targets being observed by smiling models with a pleasant character. 


\section{Method}

\subsection{Design and Participants}

40 women (mean age $=20.1$ ) were recruited from the undergraduate student population at the University of Central Lancashire and participated in return for course credit. The experiment employed a 2 (character: pleasant, unpleasant) $\times 2$ (expression: smiling, neutral) withinsubjects design, with ratings of relative attractiveness of male faces as the dependent variable.

\subsection{Materials}

All face stimuli were taken from the Karolinska Directed Emotional Faces database (Lundqvist, Flykt, \& Ohman, 1998) which comprises white, European male and female faces expressing different facial expressions in pictures taken from a range of angles. Oosterhof and Todorov (2008) rated the physical attractiveness of these faces and we used these ratings to select 16 pairs of faces (full-face images with a neutral expression) where the faces in each pair had similar attractiveness ratings. We also selected four female faces of average attractiveness (between 0 and 0.25 SD from mean). All pictures were grayscale images depicting only the head and shoulders. To manipulate character of the consorts, we composed four short character sketches, two of which presented a pleasant character and two presenting an unpleasant character.

Pleasant: This is Clare. She is a bubbly and happy person. She is often described by her friends as the social glue that binds them together. She makes people feel welcome and is always good company to have around. She always has interesting and funny stories to tell and often has her friends in tears of laughter. She is often missed by her friends when she isn't there.

Unpleasant: This is Rachel. Those who know Rachel often think of her as self-centred and manipulative. She appears friendly but would easily turn on a friend if was to her own advantage. Like many people, she enjoys gossip but Rachel uses gossip in a malicious way and often ends up hurting people. As a result, her friends don't really trust her. She can be callous and finds other people's distress and problems entertaining.

To assess the pleasantness of the character in each sketch, 15 people rated all four sketches on an 9-point scale (1: very unpleasant character, 9: very pleasant character). The pleasant characters $(M=8.37, S D=0.74)$ and the unpleasant characters $(M=1.77, S D=0.78)$ received significantly different pleasantness ratings, $t(14)=19.48, p<.001$. The assignment of character portrait to each female face was order rotated so that each face appeared with each character portrait equally often.

Following the method employed by Jones et al. (2007), we created pre-observation and postobservation slideshows which comprised 16 pairs of males faces approximately matched for attractiveness. For each pair, we asked participants to rate the degree to which they found one face more attractive than the other (see Figure 1). The pre-observation and post-observation slideshows were identical. We also created observation slideshows which presented the same 
16 pairs of male faces but with a female model between each pair (see Figure 2). In each case, the model was depicted in profile facing one of the male faces (the target face) with either a smiling expression (positive) or a neutral expression (neutral). For each observation slideshow, each model appeared with four pairs of male faces; she had a positive expression for half of these pairs and a neutral expression for the other half. To balance the direction in which the model faced, each trio of faces was presented twice so each male face appeared on both the left and the right while the model was oriented to the left and right equally often when facing the same target. Finally, the combinations of male faces, model face and model expression were fully counterbalanced so that, across the study, each male face was observed equally often by each model wearing positive and neutral facial expressions. Each trio appeared for 3 seconds.

\subsection{Procedure}

Participants were tested individually. In the pre-observation phase, we explained that they would be asked to rate which of two male faces they found more attractive. Each point on the rating scale was numbered $1-8$ (respectively: face on the left is much more attractive, more attractive, somewhat more attractive, slightly more attractive, face on the right is slightly more attractive, somewhat more attractive, more attractive, much more attractive) and the participant was asked to give a verbal numerical response to each of the 16 pairs. Each response was noted by the experimenter who then advanced slide to the next pair. Following this, participants were shown the four model women, one at a time. In each case, the face was shown both full-face and in profile, accompanied by a pleasant or unpleasant character sketch. To encourage binding of the character with the face, participants were asked to think about whether they could discern aspects of the woman's character in their facial features. After seeing all four models, participants were shown the observation phase and asked to look closely at each trio of faces in the slideshow. Immediately following this, the participant again rated the 16 pairs of male faces. They were told that the faces were the same as before but not necessarily in the same pairings, and so they should make fresh judgements about the relative attractiveness of the faces in each pairing. Finally, the participant was debriefed and thanked for their participation. All procedures followed were in accordance with the WMA Declaration of Helsinki on ethical treatment of human participants.

Data were coded in terms of the shift in preferences towards the target face from preobservation to post-observation phases; thus, positive changes indicated a shift in preferences towards the target face.

\section{Results}

Mean shifts in preference for the observed face in each combination of observer character and expression are shown in Figure 3. In terms of magnitude, it appears that the conditions involving pleasant smiling $(M=0.23, S D=0.23)$ and pleasant neutral $(M=0.11, S D=0.23)$ female faces resulted in greater shifts in ratings than unpleasant smiling $(M=-0.02, S D=$ 
$0.29)$ and unpleasant neutral $(M=0.03, S D=0.27)$ female faces. All data were entered into a 2 (character: pleasant, unpleasant) $\times 2$ (expression: smiling, neutral) repeated-measures analysis of variance. Generalised eta-squared $\left(\eta_{\mathrm{G}}^{2}\right.$; (Olejnik \& Algina, 2003)) is reported as the effect-size statistic here because it is appropriate in repeated-measures designs (Bakeman, 2005). There was a significant main effect of character, $F(1,39)=13.60, p<.01, \eta^{2}{ }_{\mathrm{G}}=.10$, indicating that that raters were more influenced by models with a pleasant character $(M=$ $0.17)$ than those with an unpleasant character $(M=0.003)$. There was no main effect of expression, $F(1,39)=0.74, p=.39, \eta^{2}{ }_{\mathrm{G}}=.003$, but there was a significant interaction between character and expression, $F(1,39)=8.01, p<.01, \eta^{2}=.03$. Pairwise comparisons showed that preference copying was higher when the pleasant model was smiling as compared to when she showed a neural expression, $t(39)=3.04, p<.01$, and compared to when the unpleasant model was smiling, $t(39)=4.44, p<.01$.

\section{Discussion}

The growing literature on mate-choice copying, or mate quality bias, has presented physical attractiveness as the central factor in determining how influential a particular woman will be to other women's preferences. Our data show that the character of the woman also exerts powerful influences on other women's preferences. Being attended to (looked at) by a smiling model with a pleasant character significantly increased ratings of physical attractiveness while models with an unpleasant character exerted virtually no effect on attractiveness ratings of the men with which they were shown. Mate-choice copying is driven by character attractiveness as well as physical attractiveness.

We predicted that pleasant smiling models would be most influential to other women's preferences, but pleasant models with neutral expressions also shifted preferences in the same direction. Previously, Jones et al. (2007) had found that smiling models increased liking of target faces while models with a neutral expression actively reduced participants' liking of target faces. However, in the present study, all models had already acquired an affective valence (through being associated with either a pleasant or unpleasant character) that was independent of their facial expression while those in the previous work were nondescript female faces with no pre-existing valence aside from their facial expression. Thus, it may be that facial expressions are more influential in the absence of any other information regarding the valence of a face stimulus; facial expressions are transient but the character in a face is more enduring, and it may be that a pleasant character with a neutral expression is still a positive stimulus with which to be associated. Indeed, the mechanism through which mate choice copying effects may alter preferences has not been clarified but proposals have centred around a mechanism which incorporates the presence of other women into desirability judgements (e.g. Hill \& Buss, 2008). In combination with other evidence (e.g. Jones et al., 2007; Place et al., 2010), the present study converges on the view that perceived interpersonal interest between model and target also plays a strong role in assessing the desirability of the target. Women with a pleasant character are more influential to other 
women's assessments of men's attractiveness when they are smiling at him as opposed to wearing a neutral expression; perceived interest appears to moderate copying.

Mate choice copying should be beneficial to people only when the preferences of the model give people more information about a potential mate than is immediately discernible. Given that men are more influenced by physical attractiveness than are women when selecting a potential partner, and that physical attractiveness is visually discernible, we would expect men to show little (or at least substantially lower levels of) mate-choice copying when selecting potential partners. However, mate-choice copying effects do not seem to be limited to women; studies of male mate-choice copying have shown a similar pattern of effects where men's ratings of female attractiveness have been affected by perceived interest from other men (Little et al., 2008; Place et al., 2010). For example, Little et al. (2008) showed that men rate female faces more highly when paired with attractive male faces than less attractive faces, but only when making judgements about long-term rather than short-term relationships. For men, physical attractiveness is an important characteristic in a potential partner but it is by no means the only desirable characteristic; for example, Li, Bailey, Kenrick, and Linsenmeier (2002) show that qualities such as kindness and intelligence are also important to men and we would expect these other characteristics to be much more influential to long-term mate-choice decisions rather than those of a more temporary nature. Nevertheless, this raises the question of whether men would be as influenced by the character of a woman's male admirers as women seem to be by the character of a man's female admirers and future work should examine this question.

Women are influenced by the opinions of other women with a pleasant character but this can only be beneficial if they are aware of the character of other women. Whilst mate-choice copying can clearly be applied amongst friends where each other's character is a known entity, it could also (perhaps more fruitfully) be applied between complete strangers because a person's character can be visually discernible from their facial features. For example, Penton-Voak, Pound, Little, and Perrett (2006) showed a relationship between self-reported extraversion and others' perceptions of extraversion in individual faces; that is, there is a degree of accuracy in assessments of a facet of other people's character based solely on their facial appearance. Several other studies have recently presented evidence in support of a relationship between character and facial appearance in humans (e.g. Kramer, King, \& Ward, 2011; Samochowiec, Wänke, \& Fiedler, 2010; Stirrat \& Perrett, 2010) and it is therefore possible that character-driven mate-choice copying can take place even when the character of the model is not explicitly known.

We have demonstrated the phenomenon of character-driven mate-choice copying in women, where women with a pleasant character are significantly more influential to other people's judgements of men's attractiveness than are unpleasant women. Further, this is moderated by perceived interest between the model and the target; women showing interest are more influential to other women's preferences than are women showing disinterest. 
References

Bakeman, R. (2005). Recommended effect size statistics for repeated measures designs. Behavior Research Methods, 37(3), 379-384.

Chu, S., Hardaker, R., \& Lycett, J. E. (2007). Too good to be 'true'? The handicap of high socio-economic status in attractive males. Personality and Individual Differences, 42(7), 1291-1300. doi: 10.1016/j.paid.2006.10.00

Eva, K. W., \& Wood, T. J. (2006). Are all the taken men good? An indirect examination of mate-choice copying in humans. Canadian Medical Association Journal, 175(12), 1573-1574. doi: 10.1503/cmaj.061367

Furnham, A. (2009). Sex differences in mate selection preferences. [Article]. Personality and Individual Differences, 47(4), 262-267. doi: 10.1016/j.paid.2009.03.013

Graziano, W. G., Jensen-Campbell, L. A., Shebilske, L. J., \& Lundgren, S. R. (1993). Social influence, sex differences, and judgements of beauty: Putting the interpersonal back in interpersonal attraction. Journal of Personality and Social Psychology, 65(3), 522531.

Hill, S. E., \& Buss, D. M. (2008). The mere presence of opposite-sex others on judgments of sexual and romantic desirability: Opposite effects for men and women. Personality and Social Psychology Bulletin, 34(5), 635-647. doi: 10.1177/0146167207313728

Jones, B. C., DeBruine, L. M., Little, A. C., Burriss, R. P., \& Feinberg, D. R. (2007). Social transmission of face preferences among humans. Proceedings of the Royal Society BBiological Sciences, 274(1611), 899-903.

Kramer, R. S. S., King, J. E., \& Ward, R. (2011). Identifying personality from the static, nonexpressive face in humans and chimpanzees: Evidence of a shared system for signaling personality. Evolution and Human Behavior, 32(3), 179-185. doi: 10.1016/j.evolhumbehav.2010.10.005

Lewandowski, G. W., Aron, A., \& Gee, J. (2007). Personality goes a long way: The malleability of opposite-sex physical attractiveness. Personal Relationships, 14(4), 571-585.

Li, N. P., Bailey, J. M., Kenrick, D. T., \& Linsenmeier, J. A. W. (2002). The necessities and luxuries of mate preferences: Testing the tradeoffs. Journal of Personality and Social Psychology, 82(6), 947-955.

Little, A. C., Burriss, R. P., Jones, B. C., DeBruine, L. M., \& Caldwell, C. A. (2008). Social influence in human face preference: men and women are influenced more for longterm than short-term attractiveness decisions. Evolution and Human Behavior, 29(2), 140-146. doi: 10.1016/j.evolhumbehav.2007.11.007

Little, A. C., Caldwell, C. A., Jones, B. C., \& DeBruine, L. M. (2011). Effects of Partner Beauty on Opposite-Sex Attractiveness Judgments. [Article]. Archives of Sexual Behavior, 40(6), 1119-1127. doi: 10.1007/s10508-011-9806-5

Lundqvist, D., Flykt, A., \& Ohman, A. (1998). The Karolinska Directed Emotional Faces. CDROM from Department of Clinical Neuroscience, Psychology section, Karolinska Institutet.

Olejnik, S., \& Algina, J. (2003). Generalized eta and omega squared statistics: Measures of effect size for some common research designs. Psychological Methods, 8(4), 434-447. 
Oosterhof, N. N., \& Todorov, A. (2008). The functional basis of face evaluation. Proceedings of the National Academy of Sciences of the United States of America, 105(32), 1108711092.

Paunonen, S. V. (2006). You are honest, therefore I like you and find you attractive. Journal of Research in Personality, 40(3), 237-249. doi: 10.1016/j.jrp.2004.12.003

Penton-Voak, I. S., Pound, N., Little, A. C., \& Perrett, D. I. (2006). Personality judgments from natural and composite facial images: More evidence for a 'kernel of truth' in social perception. Social Cognition, 24(5), 607-640. doi: 10.1521/soco.2006.24.5.607

Place, S. S., Todd, P. M., Penke, L., \& Asendorpf, J. B. (2010). Humans show mate copying after observing real mate choices. Evolution and Human Behavior, 31(5), 320-325. doi: 10.1016/j.evolhumbehav.2010.02.001

Pruett-Jones, S. (1992). Independent versus nonindependent mate choice - do females copy each other? American Naturalist, 140(6), 1000-1009.

Samochowiec, J., Wänke, M., \& Fiedler, K. (2010). Political ideology at face value. Social Psychological and Personality Science, 1(3), 206-213. doi: 10.1177/1948550610372145

Stirrat, M., \& Perrett, D. I. (2010). Valid facial cues to cooperation and trust: Male facial width and trustworthiness. Psychological Science, 21(3), 349-354. doi: $10.1177 / 0956797610362647$

Trivers, R. L. (1972). Parental investment and sexual selection. In B. Campbell (Ed.), Sexual selection and the descent of man, 1871-1971 (pp. 136-179). Chicago, IL: Aldine.

Vakirtzis, A., \& Roberts, S. C. (2009). Mate choice copying and mate quality bias: different processes, different species. Behavioral Ecology, 20(4), 908-911. doi: 10.1093/beheco/arp073

Waynforth, D. (2007). Mate choice copying in humans. Human Nature-an Interdisciplinary Biosocial Perspective, 18(3), 264-271. doi: 10.1007/s12110-007-9004-2

Yorzinski, J. L., \& Platt, M. L. (2010). Same-Sex Gaze Attraction Influences Mate-Choice Copying in Humans. Plos One, 5(2). doi: 10.1371/journal.pone.0009115 
Figure 1. Face presentation in the pre-observation and post-observation phases.
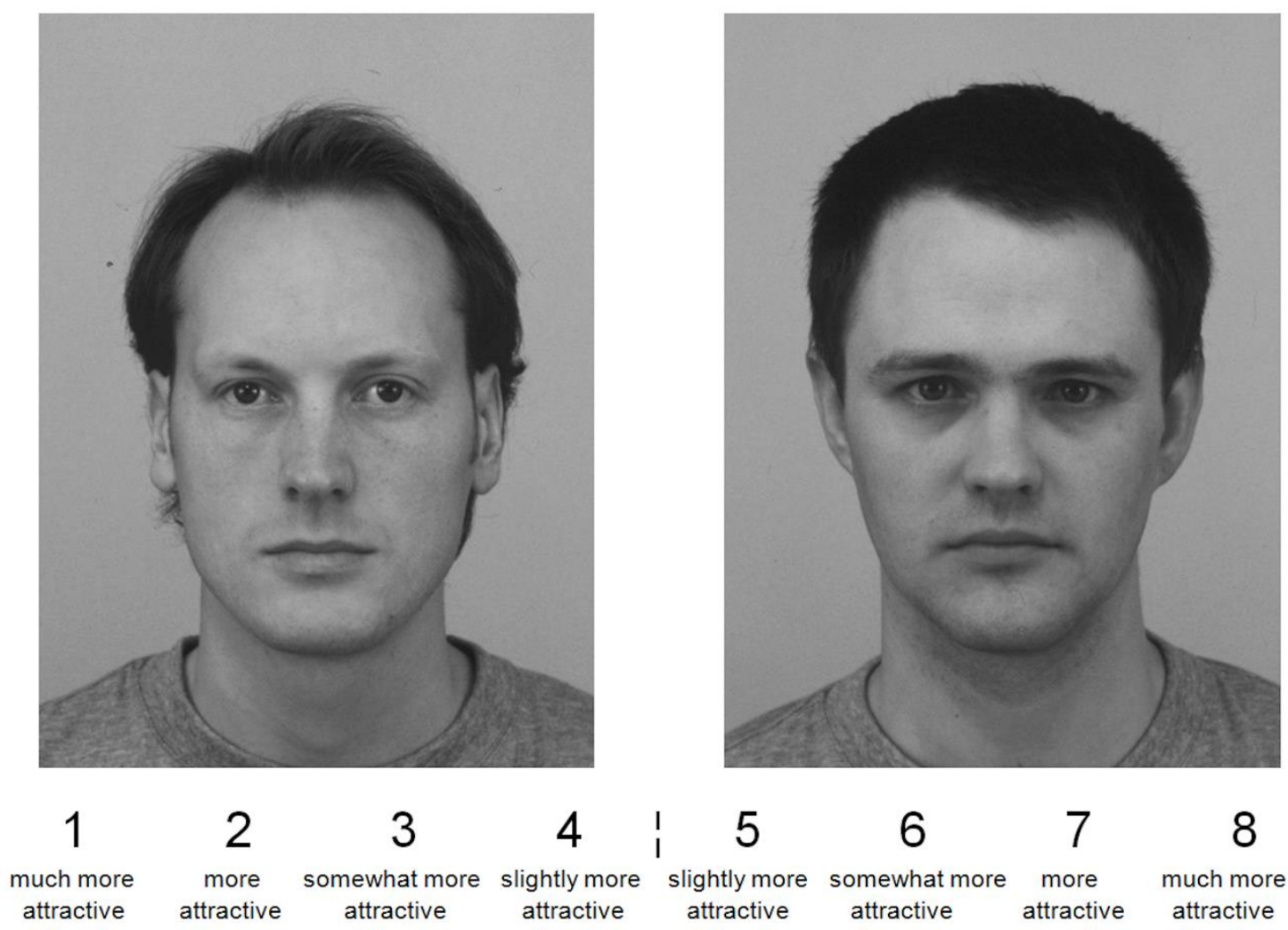
Figure 2. Face presentation in the observation phase.

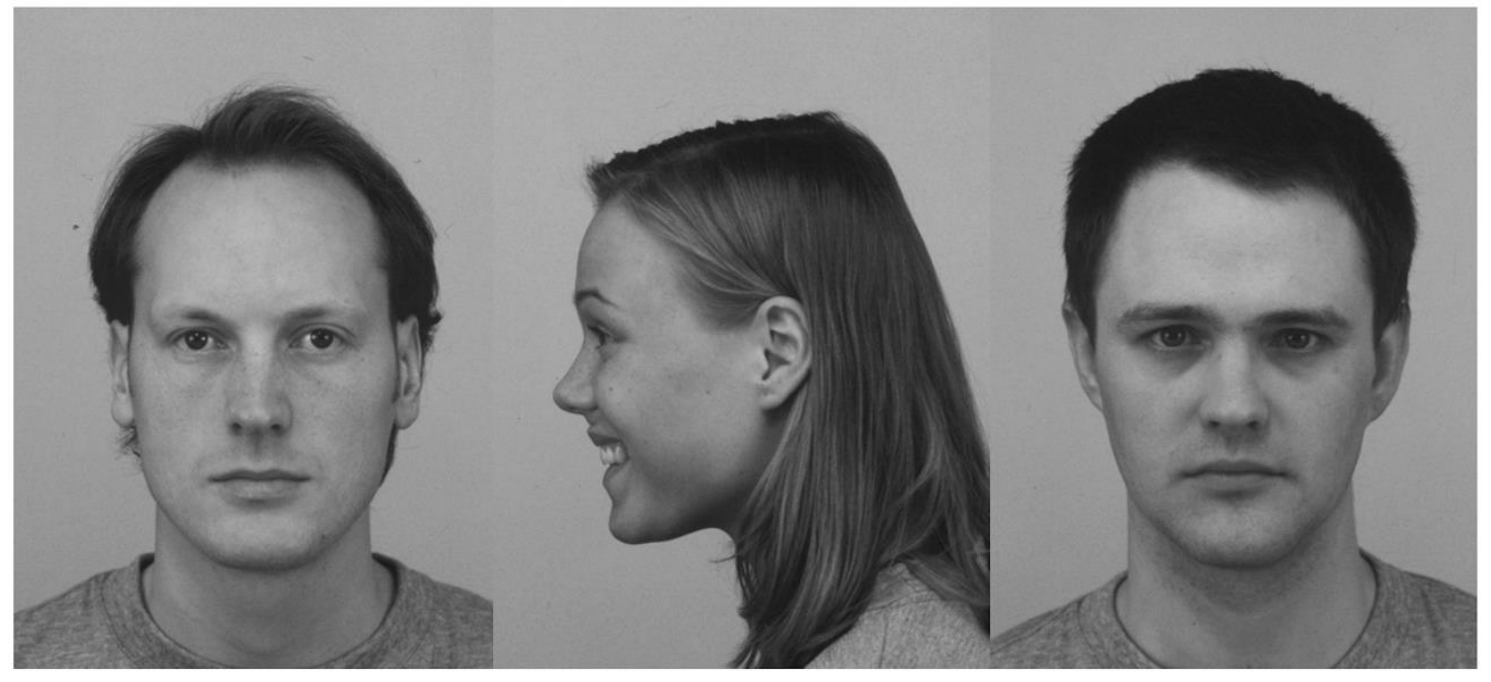


Figure 3. Mean shifts in preference (standard error) for the observed face when observed by women with pleasant or unpleasant character, and with a smiling or neutral expression.

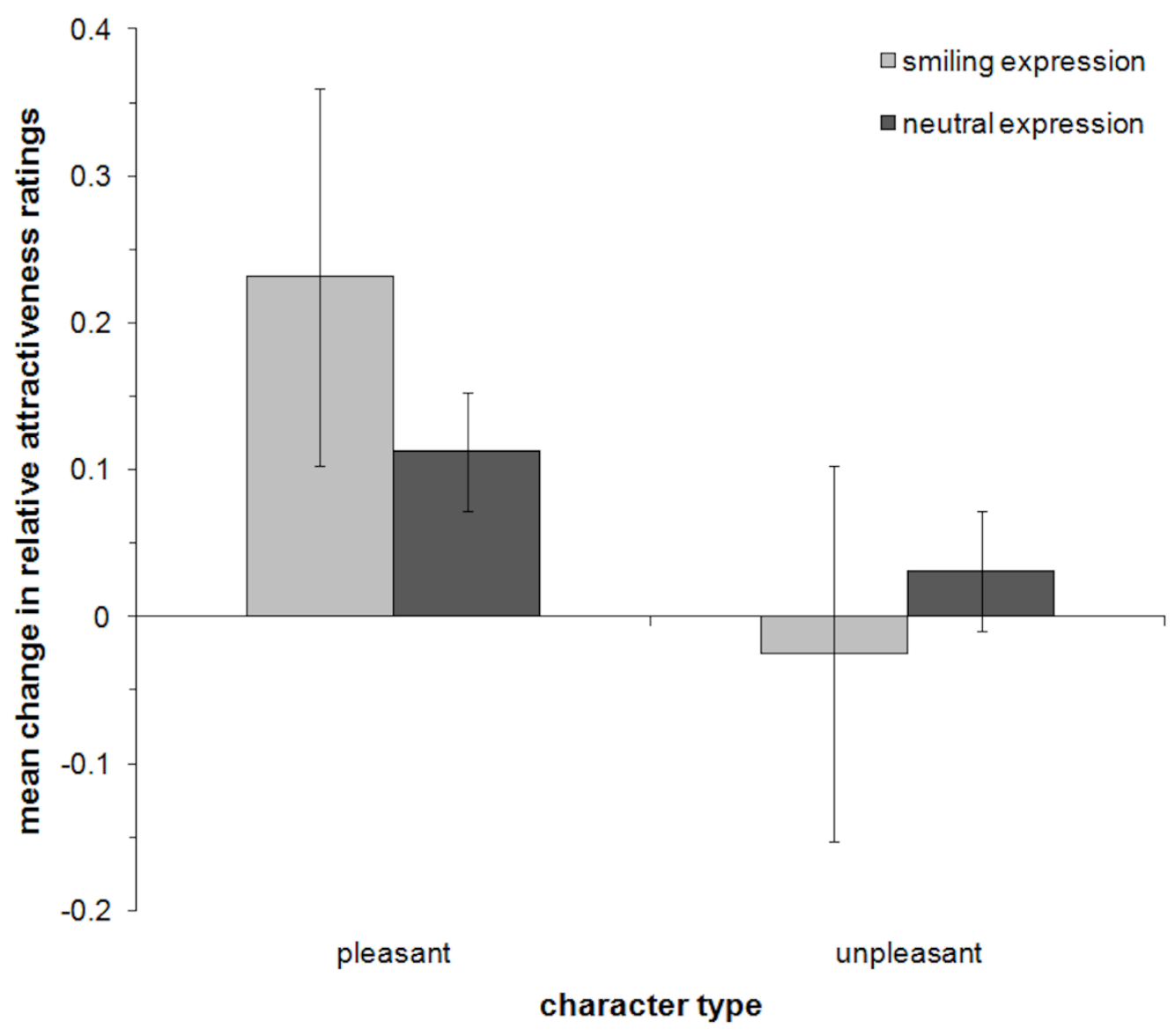

